\title{
Silvered Polymer Reflectors
}

\author{
Paul Schissel \\ H. H. Neidlinger \\ A. W. Czanderna
}

March 1985

Prepared for the

Annual Solar Thermal Research Conference Lakewood, Colorado;

20-22 February 1985

\section{Solar Energy Research Institute}

A Division of Midwest Research Institute

1617 Cole Boulevard

Golden, Colorado 80401

Prepared for the U.S. Department of Energy

Contract No. DE-AC02-83CH10093 


\section{NOTICE}

This report was prepared as an account of work sponsored by the United States Government. Neither the United States nor the United States Department of Energy, nor any of their employees, nor any of their contractors, subcontractors, or their employees, makes any warranty, expressed or implied, or assumes any legal liability or responsibility for the accuracy, completeness or usefulness of any information, apparatus. product or process disclosed, or represents that its use would not infringe privately owned rights.

Printed in the United States of America

Available from:

National Technical Information Service

U.S. Department of Commerce

5285 Port Royal Road

Springfield, VA 22161

Price: Microfiche A01

Printed Copy A02

Codes are used for pricing all publications. The code is determined by the number of pages in the publication. Information pertaining to the pricing codes can be found in the current issue of the following publications. which are generally available in most libraries: Energy Research Abstracts. (EAA); Government Reports Announcements and Index (GRA and I); Scientific and Technical Abstract Reports (STAR); and publication, NTIS-PR-360 available from NTIS at the above address. 


\title{
SILVERED POLGMER REFLECTORS
}

\author{
Paul Schissel, H.H. Neidlinger, A.W. Czanderna \\ Solar Energy Research Institute \\ Golden, Colorado 80401
}

This paper reports on the status of silvered polymer mirrors. One of the principal objectives of the SERI Solar Thermal Research Program is to develop silvered polymer films for constructing durable, low-cost, lightweight concentrating collectors for high temperature, solar thermal systems. We are guided by earlier studies [1-3] toward the following long-term goals: reflectance $90 \%$; specularity 2 mrad; 1ife 5 years; cost $\$ 15 / \mathrm{m}^{2}(1982 \$)$. Meeting these goals would permit. using silvered polymers at a cost reduction compared with glass mirrors. Silvered polymer mirrors have not yet met these goals, although the present results are very encouraging. For less demanding applications the current silvered polymers may be satisfactory.

\section{EXPERIMENTAL PROCEDURE}

The test mirror configurations are shown in Figure 1 . In one industrially available configuration (Figure 1A) optically transmitting polymer films are silvered using either sputtering or thermal deposition in vacuum. In some instances a metallic (Inconel or aluminum) or polymeric protective backing is coated onto the silver. The silvered polymer is mounted onto a substrate with an adhesive film. The various combinations for this configuration have been discussed in detail.

When the polymer formulations are being altered to compare and improve durability, it is convenient to use the solution-casting technique to make the polymeric films (FIgure $1 \mathrm{~B}$ ). The cast films are usually very thin (100-10,000 $\mathrm{nm})$, and they are used only for comparative performance studies. It is not intended that they will protect silver in durability tests like the thick, industrial films of Figure $1 \mathrm{~A}$. Mirrors of this configuration are made using Corning 7809 glass as a convenient, optically flat substrate onto which a thin, reflective silver film is deposited. Polymeric films (polymethylmethacrylate, PMMA) are then cast from solution onto the silver. A series of additives (UV screens, quenchers, antioxidants, antipermeants) can enhance the effectiveness of PMMA. We have identified a series of additives with first emphasis on $U V$ screens that have been and are being tested. 
(A)

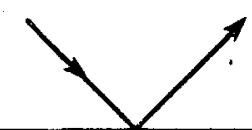

Polymer film - industrial

Silver - vacuum deposition

Backing - Inconel, polymer

Adhesive

Substrate - stainless, aluminum
(B)

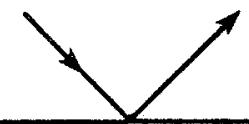

Polymer + stabilizers

Silver - vacuum or chemical

Substrate - glass

\section{Figure 1. Silvered Polymer Mirror Test Specimens}

There are several possible silvering processes. We have used vacuum metallization onto glass substrates or deposition by the wet-chemical process onto glass substrates as precursors to casting polymeric films. In this case we coat the polymer onto the silver in contrast to using extruded films where we deposit the silver onto the polymer in a vacuum. Although solution casting may not be used in large-scale production, we have observed some factors that influence optical performance; the factors are all relevant for our tests, and they may be relevant where extruded films are used. Other metallization processes e.g., ion plating, may be used if, for example, adhesion of the silver to contiguous materials is a limiting factor, but we have not yet used them.

Mirrors are characterized for their solar-weighted (air mass 1.5) reflectance using a Perkin-Elmer 340 spectrometer and integrating sphere to obtain the hemispherical reflectance $H$ from 200 to $2600 \mathrm{~nm}$. For heliostat applications specular reflectances $\mathrm{S}$ are especially relevant parameters that may be more sensitive to weathering degradation then hemispherical reflectances. Therefore, as work proceeded, we included specular measurements at one wavelength $(660 \mathrm{~nm})$ and one acceptance angle $(15 \mathrm{mrad})$. These measurements were made with a Devices \& Services* instrument, which has now been altered to obtain $S$ at a 7 mrad acceptance angle also.

After the initial reflectance measurements, mirrors are exposed to environmental degradation using three techniques. Weather-0meters** and $Q U V^{\pi}$ accelerated weathering devices provide data for comparison with data from real-time, outdoor exposure (racks facing south with a $45^{\circ}$ tilt).

*Devices and Services Co., Dallas, Tex.

**Weather-Ometer is a registered trademark of the Atlas Electric Devices Company, Chicago, Ill.

$\pi_{\text {QUV }}$ is a registered trademark of the 0-Panel Company, Cleveland, Ohio. 
The Weather-Ometer specimens, as illustrated in Figure 1 , are being subjected to UV or no UV, $60^{\circ} \mathrm{C}$, and air at $80 \%$ relative humidity. A Xenon arc lamp with a filter cutoff to match the terrestrial solar spectrum supplies the UV light. The QUV test cyclically uses $4 \mathrm{~h}$ of UV exposure (from fluorescent lamps) at $60^{\circ} \mathrm{C}$ and $4 \mathrm{~h}$ of condensed water exposure at $40^{\circ} \mathrm{C}$ (ASTM, G53-77). The accelerated weathering devices are used for comparison purposes only; it is not possible to state, a priori, which device provides the harsher test for any particular mirror material. All of our data on aging up to September 30, 1984 for silver mirrors with solution cast polymer films have been reported.

The photodegradation of polymers has also been studied using Fourier transform infrared spectroscopy supplemented with surface analysis characterization by Ion scattering spectrometry (ISS), Auger electron spectroscopy (AES), and X-ray photoelectron spectroscopy (XPS). The apparatus, methods, and results have been described in prior work that is adequately referenced [4].

\section{RESULTS AND DISCUSSION}

Our present measurement capabilities of $\mathrm{S}$ are limited to $7 \mathrm{mrad}$, and our data prior to May 1984 could only be measured at $15^{\circ} \mathrm{mrad}$ both at the one wavelength $660 \mathrm{~nm}$. Consequently our conclusions on aging are based on changes in these two specularities.

\section{Extruded Films}

The reflectivity of silvered polymer may exhibit degradation because of scattering, absorption, or surface roughness. In extruded films surface roughness occurs during the preparation of the polymer; e.g., from dies and rolls used during the extrusion. The surface roughness or scattering causes a loss in specularity, and absorption losses occur because of stabilizers and are detected by losses in the hemispherical reflectance.

Unless very special attention is paid to the formation of the polymeric film before silvering and the smoothness of the adhesive and substrate, the mirror will not have the requisite properties. The precursor film to ECP $300 X$ is the only available film that we have identified as having specularities consistently in the high $90 \mathrm{~s}$ (15 mrad). ECP $300 X$ is an experimental silvered polymer mirror made by the $3 \mathrm{M}$ Co.

\section{UV Effects}

In the Weather-Ometer studies samples can be mounted so that half of each sample is shielded from UV light while the whole sample is exposed to the temperature and humidity conditions. The sample portions exposed to UV usually degrade optically more rapidly than the half protected from UV. Since UV is known to degrade silver and PMMA, 
it is evident that the role of the UV screens has been to diminish, if not eliminate, the problem. The challenge is to be able to incorporate a UV stabilizer that is also nondegradable without altering the desired reflectance properties of the silvered PMMA. For example, the commercially available stabilized silver polymers reduce the Initial value of $\mathrm{H}$ to $85 \%$ to $90 \%$. Furthermore, their $\mathrm{S}$ values are below $90 \%$.

During QUV exposures, sample portions exposed to UV also degrade more rapidly than the half protected from UV but by orders of magnitude less than in the Weather-Ometer. Although one commercial stabilizer (Tinuvin P, Ciba-Geigy) proved to be more permanent than the other investigated stabilizers, a noticeably higher loss is observed in the UV-exposed portion versus the half protected from UV. This could indicate a photodecomposition contribution to the loss of Tinuvin P. These results from QUV studies are also confirmed by Weather-Ometer studies, where a small loss of Tinuvin $P$ as a function of time has also been observed.

Pure PMMA is highly resistant to UV degradation [4], but laboratorypure PMMA is not encountered in commercial production processes. Impurities and some additives enhance UV absorption at $>285 \mathrm{~nm}$, and accelerated polymer degradation results. One consequence of the degradation is that corrosion of the silver from atmospheric reactants can occur more readily, which probably results from an enhanced permeability of the atmospheric reactants. Impurities at the silverPMMA interface also cause polymer degradation as well as degradation of the silver; chlorine has been specifically identified, and a synergism between chlorine, silver, and UV can enhance the polymer degradation rate by factors in excess of $1000 \mathrm{X}$ [4]

Thin silver films transmit some UV light (Figure 2), and it is thought that bubbles formed during accelerated tests of some mirrors resulted from UV attack on the underlying adhesive. The bubbling problem can be eliminated by using increased amounts of UV screen in the front polymeric coating or by using a back coating of Inconel to absorb the UV. However, the $H$ and $S$ are either reduced by the screen, or the $S$ degrades more rapidly during accelerated testing by using Inconel.

\section{Metallization}

There are several possible silvering processes. We have used vacuum metallization either by sputtering or thermal evaporation on extruded films and on glass substrates as the precursor to casting polymeric films. We have used deposition by the wet-chemical process only on glass substrates, again as a precursor to casting polymeric films. The wet-chemical process can be used on polymers, and preliminary attempts have been made to use it for mirror fabrication [5]; however, it has not been demonstrated that mirrors of the necessary quality can be made by this process. Either of the vacuum metallization processes produces excellent mirrors, and the specularity ( 7 or $15 \mathrm{mrad}$ ) is not affected by deposition rates of 0.1 to at least $3 \mathrm{~nm} / \mathrm{s}$. 
When silver is deposited onto glass by the wet-chemical process used to make household mirrors, the hemispherical reflectance of the silver at the silver-air interface falls to about $88 \%$ after coating the silver with PMMA. (Note the silver-glass interface would be used if it were a "glass" mirror.) This compares to the initial hemispherical reflectance of about $96 \%$ for the uncoated silver mirror. In a series of experiments it was demonstrated that the decrease in reflectance using wet-processed silver is not a chemical effect. For example the reflectance of the silver returns to its original value of $96 \%$ when the PMMA films are redissolved with the same type solvent. The transmittance of the redissolved polymer compared to the original polymer solution is also unchanged. Alternatively, we have also shown that when the silver is deposited onto glass by vacuum sputtering rather than the wet-chemical process, we obtain reflectances in the mid-90s, and this value remains when PMMA films are cast onto sputtered silver in the same way they were placed onto wet-processed silver.

The decrease of reflectance of PMMA-coated, wet-process silver mirrors manifests itself visually as a slight yellow hue that is not present when vacuum-sputtered silver is used. The yellowing phenomenon is observed for different types of polymers or when a drop of solvent (toluene) is deposited onto bare silver. The effect on reflectance is illustrated in Figure 3, where the initial hemispherical reflectance of $\mathrm{PMMA} / \mathrm{Ag} / 7809$ glass is shown as a function of wavelength. The reflectance minimum at $400 \mathrm{~nm}$ is absent when sputtered silver is used.

Scanning electron microscopy studies have shown that the surface of wet-processed silver is rougher than that of sputtered silver (Figure 4). This surface roughness, together with possible crystalline disorder in the silver surface, provides a coupling of incident light to surface plasmons (collective electron excitations

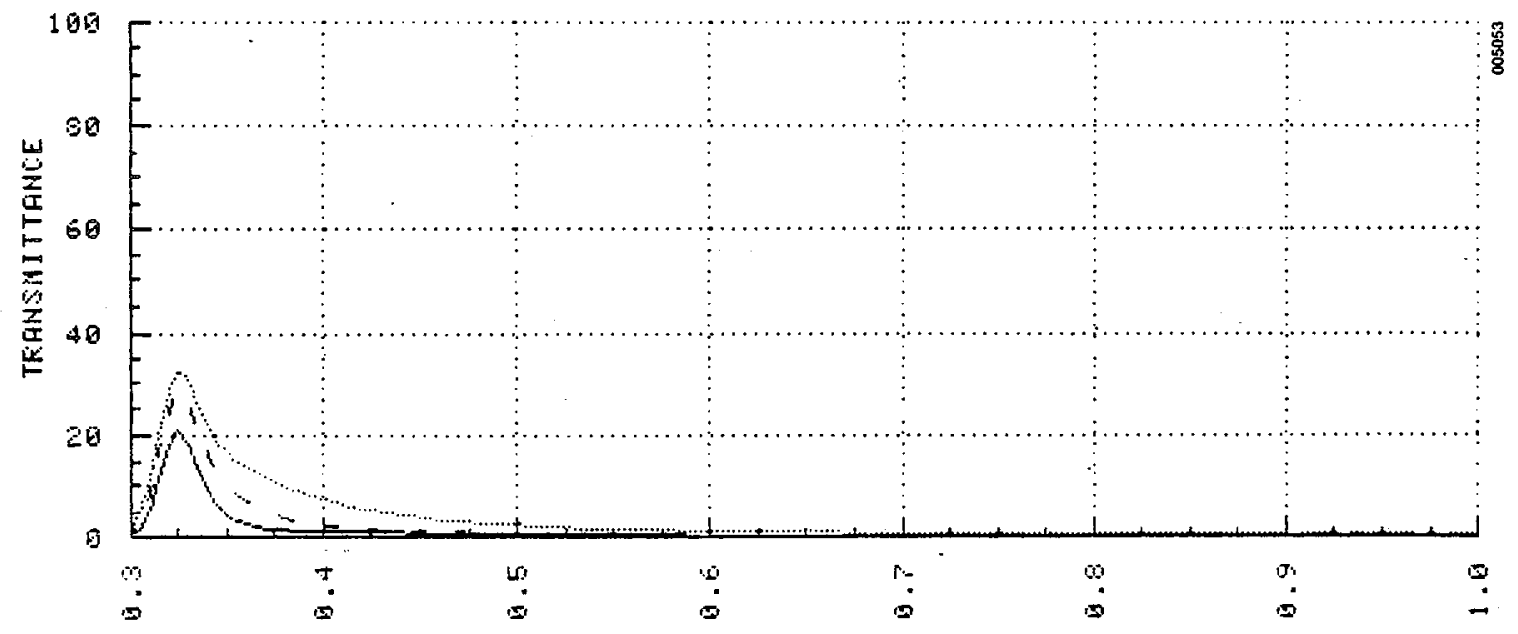

WAWELENETH MMICROMETER!

Figure 2. Transmittance of Uncoated and Coated Silver Mirrors 
localized near the silver surface [6]). Excitation of the surface plasmons in turn gives rise to increased absorption and scattering in some wavelength regions.

When an Inconel backing is deposited onto the silvered polymer, specularity measurements at 15 mrad showed essentially no change compared with samples with no Inconel. However, at a 7 mrad acceptance angle, losses in specularity result and are even detectable for silvered glass where the loss in optical performance is enhanced by weathering. No study has been made to determine the cause, but the
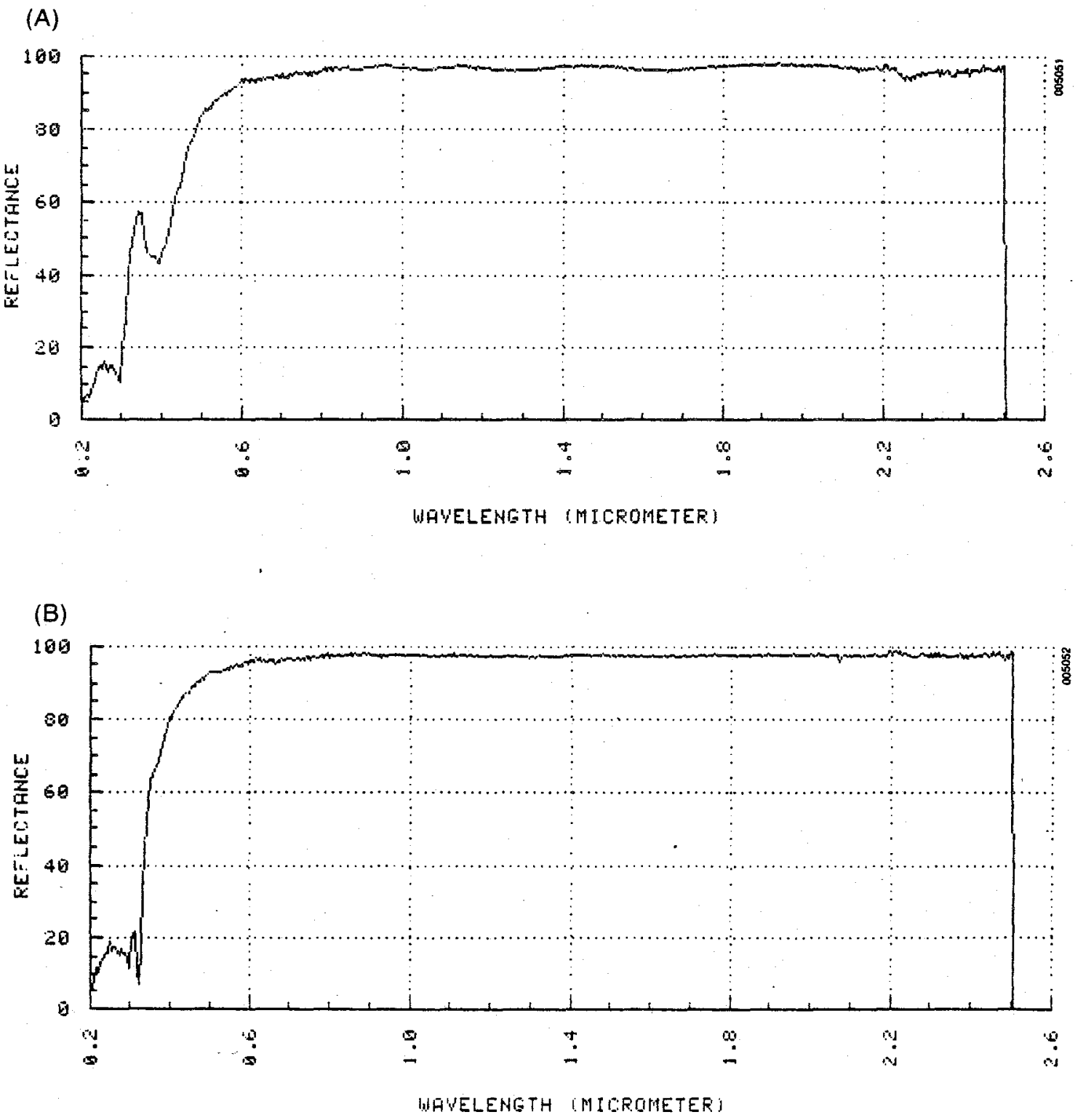

Figure 3. Reflectances of (A) PMMA/Wet-Processed Ag/7809 Glass and (B) PMMA/Sputtered Ag/7809 Glass 
specularity losses are thought to result from stresses imposed by the Inconel onto the silver. It is known that mechanical stresses alter the optical properties of thin films.

\section{Bffects of Polymer Additives}

The characteristics of photodegradation permit application of methods to prevent such degradation by involving both photon absorption and transfer of energy. Generally, photostabilizers for polymers are classified according to their mode of action: UV light absorbers, excited state quenchers, antioxidants, and hydroperoxide decomposers. A series of additives has been identified and incorporated into PMMA to enhance its effectiveness. The initial emphasis has been on using UV absorbers, combinations of UV absorbers, and hindered amine light stabilizers or antioxidants.

Analysis of the data identifies Tinuvin $P$ as a leading stabilizer for PMMA/silver mirrors. Several other combinations are comparable to it based on these Weather-Ometer results: Givsorb UV2 + Tinuvin 292, National Starch 78-6121 + Goodrite 3034, and National Starch 78-6121 + Goodrite 3125. There is evidence that a synergistic protection mechanism becomes operable whenever a hindered amine stabilizer, an antioxidant, and a UV screen are added to the polymer. No degradation was observed for samples shielded from the UV light except for unstabilized PMMA.

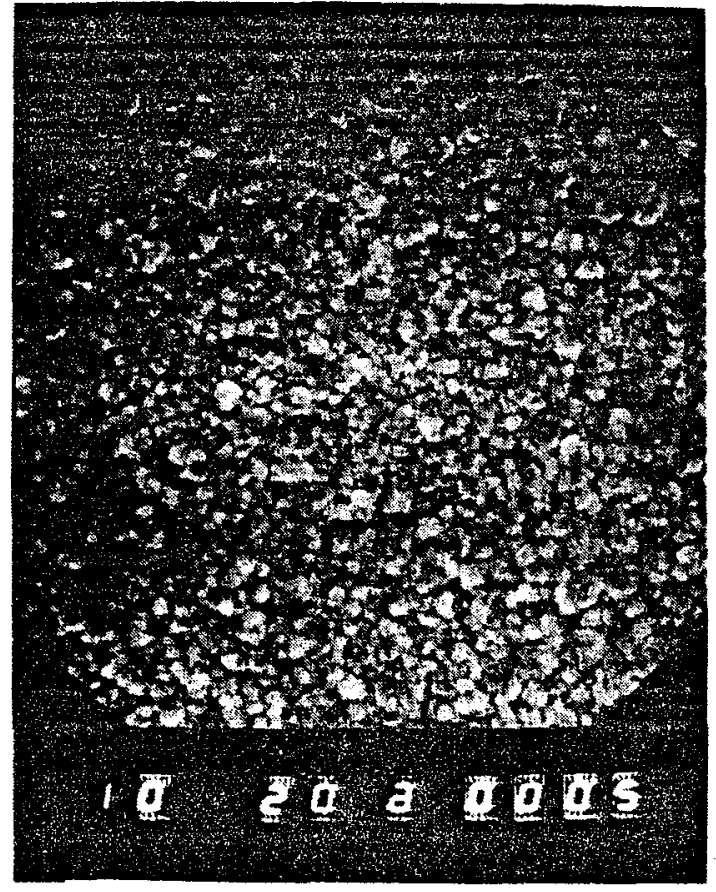

Wet

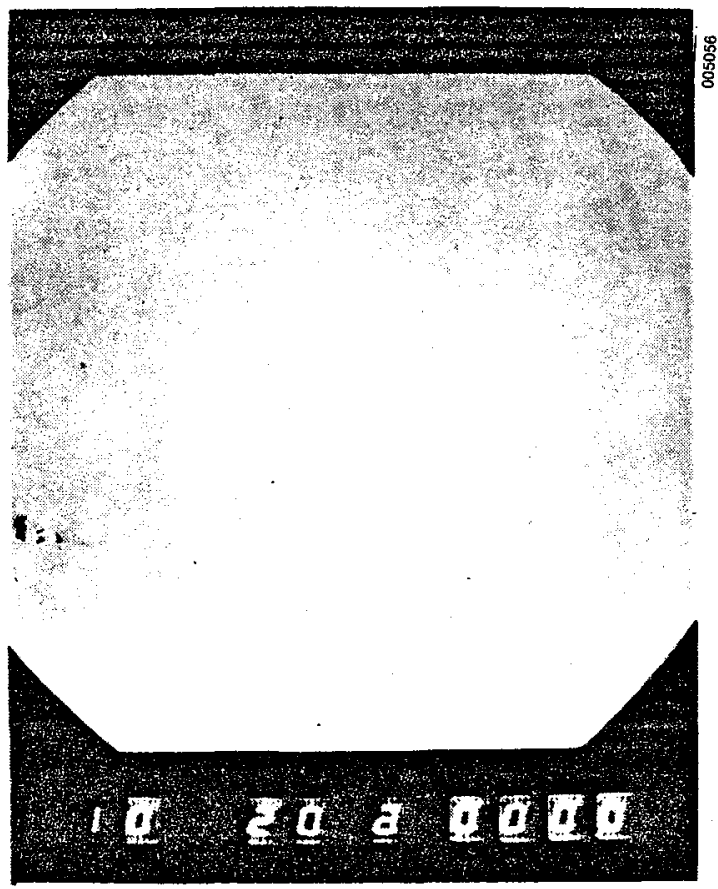

Sputtered

Figure 4. Scanning Electron Micrographs of Wet-Processed and VacuumSputtered Silver on 7809 Glass 
Results for some of the best performers are listed in Table 1 and Figure 5. The three ECP300X samples, weathered outdoors for 51 weeks, are essentially unchanged visually compared with an unweathered witness sample. The specular reflectances degrade slowly with time.

Two solution cast films are also listed in Table 1. The PMMA film (thickness $3800 \mathrm{~nm}$ ) plus stabilizer performed well up to about 42 weeks but was degraded at 64 weeks. The PAN (polyacrylonitrile) film is being studied at the University of Denver [7]; it shows good specularity both initially and after short outdoor exposures.

Other ECP300X samples supplied by the $3 M$ Co. were measured for specularity to $1 \mathrm{mrad}$ by $\mathrm{Dr}$. R. Pettit"s group (SNL, Albuquerque). The best single result is plotted in Figure 5. Both curves relate to the same mirror, and they show the optical anisotropy of the mirror surface. The mirror is measured in one orientation and then rotated $90^{\circ}$ and remeasured. The difference in reflectance is attributed to the formation of nonuniform surface marks on the polymer during fabrication. The upper curve shows that an initial specularity of $90 \%$ at $2 \mathrm{mrad}$ is attainable.

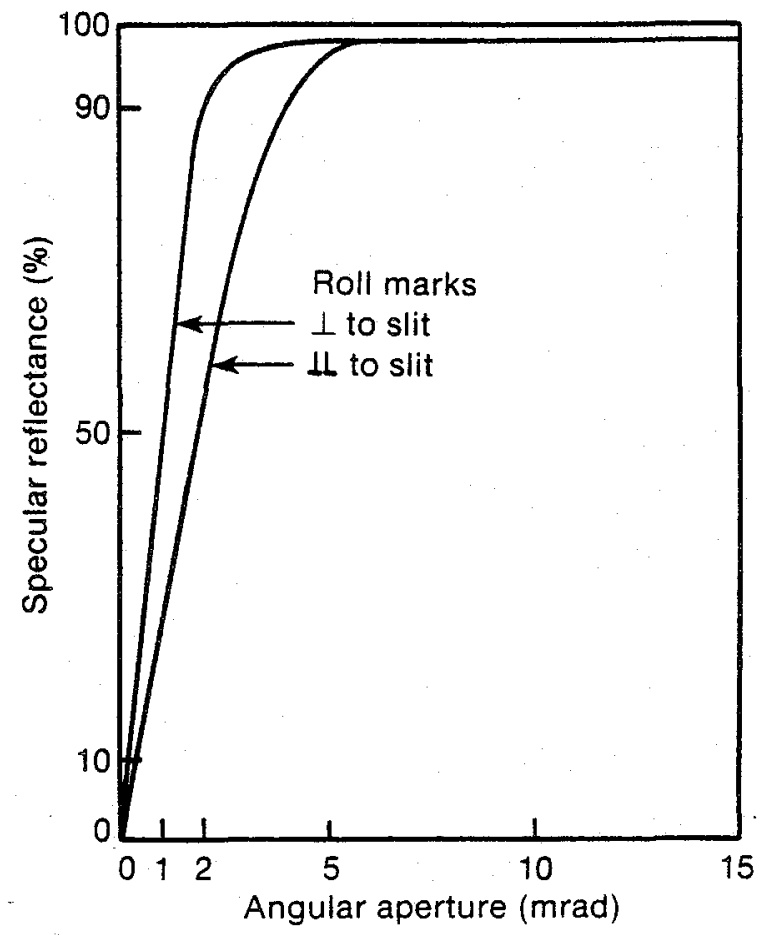

Figure 5. Specular Reflectance of Unweathered ECP300X, 3M Co., versus Acceptance Angle, Parallel and Perpendicular to Roll Marks (measurements Courtesy of Dr. R. B. Pettit, Sandia National Laboratories) 
Table 1. Best Performers - Durability Weathered Ourdoors

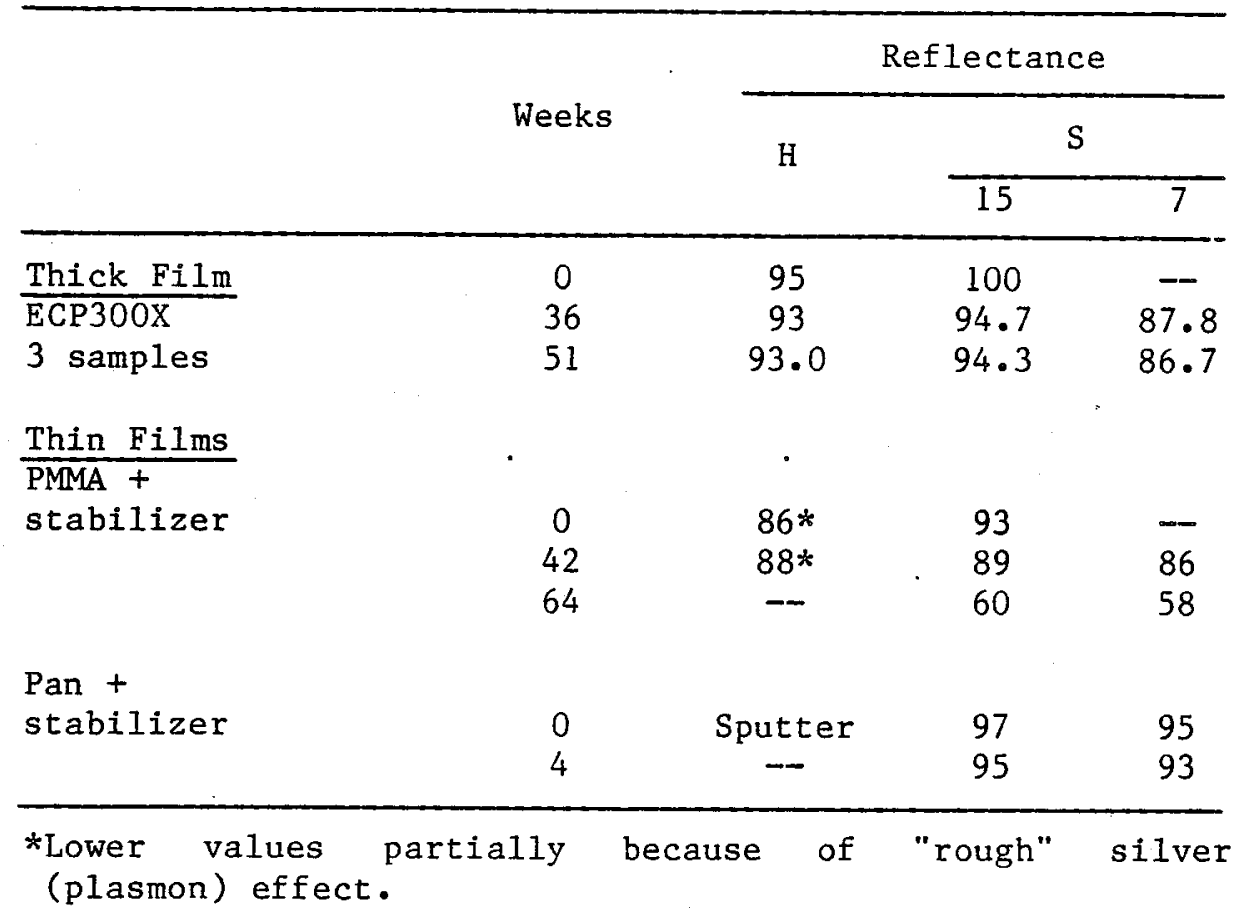

\section{ACKNOWLEDGMENTS}

The authors thank Mr. B. A. Benson, 3M Co., and Dr. R. B. Pettit, Sandia National Laboratories, Albuquerque, for supplying test samples and optical measurements, respectively, for the ECP300X mirrors. Thanks are also due to Prof. D. M. Smith and Dr. A. R. Chughtai, University of Denver, for supplying information on the polyacrylonitrile films and to R. Goggin and B. Hovermale who prepared the PMMA samples and conducted the laboratory measurements.

\section{REFERENCES}

1. Murphy, L. M., Technical and Cost Benefits of Lightweight, Stretched-Membrane Heliostats, SERI/TR-253-1818, Golden, CO: Solar Energy Research Institute, May 1983.

2. DeLaquil, P. and J. V. Anderson, The Performance of HighTemperature Central Receiver Systems, Sandia National Laboratories, Report \#SAND84-8233, July 1984 .

3. Eicker, P. J., et al., Design, Cost and Performance Comparisons of Several Solar Thermal Systems for Process Heat, Sandia National Laboratories, Livermore, CA, Vols. I through V (SAND 79-8283), April 1981. 
4. R. B. Pettit, C. N. Vittitoe, and F. Biggs, "Simplified Calculational Procedure for Determining the Amount of Intercepted Sunlight in an Imaging Solar Concentrator," J. Solar Energy Engineering, Vol. 105, February 1983.

5. Schissel, Paul, H. H. Neidlinger, and A. W. Czanderna, Identification of Chemical and Physical Phenomena Causing the Degradation of Silvered PMMA, SERI/PR-255-2493, Golden, CO: Solar Energy Research Institute, Final Draft, September 1984.

6. Neidlinger, H. H., Paul Schissel, Solar Thermal Technology Program: Polymer Synthesis and Modifications Subtask; FY 1984 Annual Progress Report, Golden, CO: Solar Energy Research Institute, Final Draft, January 1985.

7. Webb, J. D., P. Schissel, T. M. Thomas, J. R. Pitts, and A. W. Czanderna, Polymeric Degradation of Reflecting Metal Films-: Fourier Transform Infrared (FT-IR) Reflection Absorbance Studies, SERI/TP-255-2054, Golden, CO: Solar Energy Research Institute, July 1983. Also in Solar Energy Materials, Vol. 11, 1984, in press.

8. Brauman, S. K., D. B. MacBlane, and F. R. Mayo, Reactivity of Polymers with Mirror Materials, Annual Report No. 2, SRI International, Project PYD-1124, Contract XP-9-8127-1, for Solar Energy Research Institute, September 1982.

9. Bennett, H. E., and J. L. Stanford, J. Res. NBS, Vol. 80A, 1976, p. 643 .

10. Sergides, C. A., et al., Relationship Between the Functional Group Concentrations and the Infrared Reflection-Absorbance of Silver Backed Polyacrylonitrile Films, J. Polymer Sci., Polymer Physics Ed., in Press. 